\title{
Short-term management of repeated self-harm in secure institutions ${ }^{\dagger}$
}

\author{
Jaydip Sarkar
}

\begin{abstract}
SUMMARY
The challenge of managing repeated self-harm and the high risk of morbidity and mortality are compounded in forensic patients, where there are additional risks of harm to others, absconding and security breaches. There is an urgent need for clinically sound, practice-based and theoretically grounded strategies for managing these associated risks. This is essential as available UK guidelines appear inadequate for this group of patients. This article promotes a pragmatic approach to assessing the risk of self-harm clinically to arrive at hierarchical risk judgements. It further suggests an algorithmic approach to managing these risks and provides testable strategies that can be adapted for use in various secure institutions.
\end{abstract}

\section{DECLARATION OF INTEREST}

J.S. was a member of the group that created the management model described in this article.

Suicide is one of the ten leading causes of death worldwide and will represent about $2.4 \%$ of the global burden of disease by 2020, with about 1.5 million people dying by suicide each year (Reulbach 2008). Between 2000 and 2004, there were 23477 suicides in the UK, a rate of 10.2 suicides per 100000 for the entire population (Appleby 2006). Despite this, information to guide prevention strategies is limited (Gunnell 2010).

This article addresses risk assessment and immediate and short-term management of selfharm and attempted suicide by individuals with a primary diagnosis of personality disorder comorbid with other Axis I disorders, who have been convicted of violent offences or have a history of significant violence towards others. It does not discuss longer-term management of self-harm.

\section{Predictors of suicide following self-harm}

A history of self-harm is the strongest predictor of future suicidal behaviour (Zahl 2004). Compared with self-poisoning, suicide attempts involving hanging or strangulation, drowning, firearms use, jumping from a height or gassing are associated with a moderate to strong increase in risk (Runeson 2010). In the Runeson et al cohort study of 48649 individuals followed up for 21-31 years, continuity of method between the index suicide attempt and the eventual successful suicide (cutting, hanging, poisoning) was observed. This finding was most robust for hanging, drowning, jumping from heights and use of firearms (in men). For self-cutting and self-poisoning, the risk of eventual suicide was lower, suggesting that some self-harm acts are more lethal than others and their prevention is likely to lead to a greater avoidance of deaths.

Mental disorders, particularly affective disorders and schizophrenia, are associated with the two highest rates of completed suicide (National Confidential Inquiry into Suicide and Homicide by People with Mental Illness 2009). However, individuals with mental health problems such as personality disorders, substance and alcohol use disorders and anxiety/adjustment disorders - the so-called 'minor' or 'neurotic' cluster of disorders - collectively represent a higher-risk group than those with schizophrenia (Appleby 2006).

\section{Self-harm and suicide in prisons and secure hospitals}

The rates of life-threatening self-harm and suicide are relatively higher within secure institutions that care for mentally disordered offenders such as prisons and secure hospitals in the National Health Service (NHS) and the independent sector (Brooker 2010; Sarkar 2011a).In the vast majority of cases, self-harm by people presenting to a general hospital involves an act of self-poisoning or self-cutting, methods with lower relative risks of suicide. (Runeson 2010). In addition, patients presenting to accident and emergency (A\&E) departments are 'treatment seekers' and therefore motivated to seek help at the time of the act. On the other hand, patients in secure institutions often self-harm in secret (Uppal 2009): they tend to use high-risk methods of self-harm and often refuse to be helped. The risk of assaults on staff by patients when they try to prevent and manage such acts is well known (Uppal 2009), with a major impact on staff morale and capacity to care (Howard League of Penal Reforms 2003). Finally, in most cases, no one other than the patient is responsible for the
Jaydip Sarkar is a consultant forensic psychiatrist at the Personality Disorder and Secure Women's Services, Leicester. Correspondence Dr Jaydip Sarkar, Consultant Forensic Psychiatrist, Personality Disorder and Secure Women's Services, East Midlands Centre for Forensic Mental Health, Arnold Lodge, Cordelia Close, Leicester LE5 OLE, UK. Email: jay. sarkarjay68@gmail.com

${ }^{\dagger}$ For related articles in Advances, see Wood A (2009) Self-harm in adolescents, 15: 434-441, and its commentary, Dogra N (2009) The challenges of managing self-harm effectively, 15: 442-443. Ed. 
behaviour and its consequences (including death), even though professionals may be criticised for not being able to prevent it.

\section{In-patient suicide}

In-patient suicide is a major indictment of service providers regarding their capacity to manage vulnerable patients in their care and leads to the questioning of the credibility of individuals and institutions managing such incidents. The following paragraphs provide figures on in-patient suicides across all wards in England and Wales (including patients on general adult, forensic and learning disability wards).

Between 2000 and 2004, there were 6367 patient deaths, which represented $27 \%$ of all suicides. Of these, $14 \%$ (856) were in-patients, a rate of 180 in-patient suicides/year (Appleby 2006). However, in recent years there has been a major reduction in rates of suicide which is indicative of better awareness and more robust management of this problem. There was a 36\% fall in in-patient suicides over the period 1997-2006 (National Confidential Inquiry into Suicide and Homicide by People with Mental Illness 2009).

The most common methods used in successful suicides were hanging (65\%) and self-strangulation (30\%). Usually, everyday objects were used: belts (in $45 \%$ cases), bed-sheets or towels (16\%), shoelaces (10\%), clothing $(10 \%)$ and other materials used to tie knots (16\%). Of those who took their lives while hospital in-patients, $29 \%$ ( $n=251$ ) died on-ward and $27 \%$ off-ward. Twenty-two per cent (188 suicides) of these patients had been under special nursing observations at the time they killed themselves. This highlights indirectly the swiftness with which such incidents occur, and patients' capacity and willingness to be evasive about their real

BOX 1 Prison security categories in England and Wales

\section{Men}

Category A - prisoners whose escape would

be highly dangerous to the public/national security

Category B - prisoners who do not need maximum security but for whom escape needs to be made difficult

Category $\mathrm{C}$ - prisoners who cannot be trusted in open prisons but who are unlikely to escape

Category D - prisoners who can be trusted not to escape and given the privilege of an open prison intentions. The two major recommendations of Avoidable Deaths (Appleby 2006) were:

1 more rigorous use of nursing observations to manage access to implements of self-harm, especially potential ligature materials;

2 removal of all ligature points.

Since 2006 , there has been a $48 \%$ reduction in deaths by hanging/strangulation (National Confidential Inquiry into Suicide and Homicide by People with Mental Illness 2009).

The two most common diagnoses in those who died by suicide were affective disorders (46\%) and schizophrenia (19\%). However, a large proportion of patients (29\%) had diagnoses of personality disorder, drug and alcohol misuse, and anxiety and adjustment disorders (Appleby 2006). Those with a history of self-harm were more than four times likely to kill themselves than those who did not have this history (odds ratio of 4.3).

\section{Secure institutions}

In England, these include the three national high secure hospitals, Broadmoor, Rampton and Ashworth, and many medium and low secure units in the NHS and the independent sector. Prisons are also included, classified into four security categories that differ for men and women (Box 1). The categories are based on a combination of the crime committed, the length of sentence, the likelihood of escape, and the danger to the public if a prisoner succeeds in escaping. High secure prisons are also known as Category A prisons. The three NHS high secure hospitals have security standards commensurate with Category B prisons, whereas most medium secure units are of the level of Category C prisons. Low secure units are similar to Category D prisons.

Secure institutions within the health setting can significantly restrict access to means by which suicide is committed. Thus, patients can be denied access to sharp items (blades, cutlery, glass that can be broken into shards, plastic, CDs, pens, etc.), ligating items (belts, shoelaces, clothes, linen and toiletries that can be easily torn or adapted for use, electric cords, pyjama cords, etc.), chemicals (e.g. prescription and illicit drugs, washing, cleaning and toiletry materials), and objects that can be easily swallowed (batteries, small pieces of jewellery, coins, reading glasses, etc.). This is not possible within a prison setting which has its own challenges.

Second, patients can be placed on high levels of observation in healthcare settings and occasionally, for limited periods, in prisons too. This may include direct visual and verbal checks $24 \mathrm{~h}$ a day. 
For patients who are assaultive towards staff, the number of observation staff can be increased to two or even three to one patient (2:1 or 3:1 observation). If the risks to others are significant, patients can be managed in seclusion. Prison inmates are kept in isolation in segregation cells where they are constantly monitored directly or through CCTV. These cells can be unlocked if enough members of prison staff are available to manage risks of violence to others. If, for example, three members of staff are assigned to the individual, this is called a 'three-man unlock'.

One difficulty in depriving patients/inmates of access to 'usual' methods of self-harm is that they will find other, more creative methods (Runeson 2010). Sometimes the damage caused by these innovative methods is more physically harmful, for example patients swallow batteries or washing or cleaning agents as they do not have access to paracetamol, or try to cut themselves with blunt objects (pens) rather than with sharp blades. Secure institutions have to manage a wide array of seriously damaging acts of self-harm even when the suicidal intention may be low. The situation is very different in prisons, where it is often impossible to limit access. In such situations, inmates often carry out acts of serious self-harm with dangerous consequences.

\section{Rates of self-harm and suicide}

Self-harm rates are known to be higher in secure settings than in the community or general medical and psychiatric settings (Walsh 2009). Approximately $80 \%$ of 'self-inflicted deaths' by prisoners receive a suicide or open verdict at inquest (Brooker 2010). Meltzer et al (2002) found a prevalence of non-fatal self-harm of $7 \%$ among male sentenced prisoners and 10\% among female sentenced prisoners. Among males, the highest prevalence was in young offenders' institutions (10\%). A recent review suggests that the 3 -year annual average rate per 100000 prisoners has decreased steadily by nearly $27 \%$, from 124.1 in 2003 to 90.7 in 2008 (Brooker 2010). A systematic review of risks associated with self-inflicted deaths in prisons identified the following factors (Fazel 2008):

- inmate in a single cell leading to social isolation

- recent suicidal ideation

- history of attempted self-harm

- having a psychiatric diagnosis

- history of alcohol misuse.

Prisoners with the highest rates of self-harm are those with personality disorders or substance use disorders (Gulland 2007).
With regard to gender, women not only carry out far more acts of self-harm than men, although suicide is far more common among the latter (National Confidential Inquiry into Suicide and Homicide by People with Mental Illness 2009), but one study from a high secure hospital (Rampton) suggests that women are also responsible for a disproportionately high rate of violence towards staff and peers (Larkin 1988). This study revealed that although women constituted only a quarter of the patient population, they were responsible for three-quarters of all aggressive incidents against self and others. A follow-up study revealed that nearly $31 \%$ of all incidents in this high secure hospital were related to self-harm (1749 incidents over a 16-month period), a very large majority involving female patients (Uppal 2009).

\section{Subjective v. objective risk assessment approaches}

Repeated self-harm is a behaviour, not an illness, and there are no generally accepted standards for its management. Not surprisingly, a range of locally developed risk assessment and management strategies are in use (Sarkar 2010). These strategies often respond to the individual patient's psychopathology and stated intentions. Management may be relatively straightforward when the psychopathology of the disorder has clear, well-validated and treatment-specific approaches (e.g. depression, schizophrenia, bipolar affective disorder). However, for diagnoses of personality disorders and their comorbidities with Axis I disorders and multiple underlying motivational factors (National Collaborating Centre for Mental Health 2004), management is complex and challenging. A risk assessment screening tool for self-harm and suicide created for staff and physicians in A\&E is a good starting point and should be followed as a guide in secure units. Areas covered by the risk assessment are summarised in Box 2. Most, if not all, secure institutions have risk management strategies that cover these areas routinely.

\section{Subjective assessments: patient self-report}

Determining the intention of someone who selfharms is the first step in risk assessment. Intention in self-harm is such a subjective matter that it is often difficult to gauge other than by asking the individual directly. Therefore, risk assessments have historically been driven by patients' subjective reports of intention to harm. One such approach is a harm-minimisation programme (for women in a high secure hospital) called Trauma and Self Injury (TASI), which is funded by the National 
BOX 2 Gold standard for the management of self-harm in accident and emergency departments

- Careful history of events surrounding self-harm

- Concentrate on factors indicating intent

- Previous mental health problems

- Substance misuse, current and past

- Social circumstances and problems

- Can family be recruited to help?

- Forensic history and a mental state examination

- Depression, current suicidality and plans or intent to self-harm again

(Mitchell 2006

Institute for Health and Clinical Excellence (NICE; www.nice.org.uk/usingguidance/shared learningimplementingniceguidance/examplesof implementation/eximpresults.jsp?o=359). The details, effectiveness and wider generalisability of this approach outside high secure hospitals are unavailable at the time of writing. The programme recognises that although self-harm is a coping strategy to deal with present overwhelming distress, by applying principles of collaboration and empowerment, alternative coping skills can be developed instead of trying to control the selfharming behaviour. Integral to the approach is the so-called 'distress signature' wherein patients provide subjective accounts of a desired positive self that they will work towards while simultaneously making carers/staff aware of triggers and cues in their environment which causes them distress and leads to self-harm.

Reliance on subjective patient reports can be hazardous as these are unreliable during states of heightened arousal and widely fluctuating emotional states, as is most often the case just before (and during) self-harm acts (Nisbett 1997; Klonsky 2007). 'Don't know' answers are the most common responses clinicians get while trying to assess the motives behind self-harm in the A\&E setting. Patients are also known to carry out acts for interpersonal influence and, on occasions, emotional blackmail (Klonsky 2007). Some patients engage in self-harm as a means of encouraging staff intervention, which then provides the opportunity to assault the intervening staff (J. Wallace, personal communication, 2010). They can therefore be expected to sometimes make spurious claims of an intention to self-harm in order to exercise interpersonal control over others or meet pathological dependency needs (Gallagher 2010). The converse is also true - patients make seemingly non-lethal attempts despite high intentionality.

\section{Objective assessments}

The above might suggest that it is prudent to rely on objective perceptions of staff/others when determining intention to die by suicide. Experience suggests that it is important not to rely on staff perceptions alone in making risk judgements as counter-transference issues can prejudice and compromise objectivity (Sarkar 2010). Staff often feel deskilled in the face of repeated self-harm, despite spending long periods of time working with their patients/offenders. This can lead to a feeling of resignation and their rejection of the patient (Short 2009; Tantam 2009). Staff also experience high levels of stress and burnout which can compromise objectivity (Perseuis 2007). Prison staff, for example, have a negative attitude towards self-harm, which they consider to be 'attention-seeking' and therefore not a serious problem (Short 2009) worthy of risk management interventions. Most suicides by patients being cared for in hospital tend to occur when clinical teams underestimate the risks and grant patients access to objects and spaces within or outside of the hospital to which they do not usually have access (Appleby 2006): many such patients are on special nursing observations at the time.

In an attempt to avoid the pitfalls of individual judgements, many trusts and prisons have developed their own risk assessment tools to allow clinicians to be more structured in their assessments. The Royal College of Psychiatrists (2010) discourages the use of locally developed questionnaires of 'questionable reliability' and recommends the use of 'well-validated' psychometric instruments. Unfortunately, suicidal intent is a poor predictor of suicide in patients who self-harm, with only a positive predictive value of $4 \%$ using the Beck Suicide Intention Scale (Harriss 2005).

\section{Methods used v. reasons why}

There are two approaches to self-harm management and suicide prevention. One is to try to prevent suicides and serious and enduring physical damage. The other is to teach patients alternative coping strategies for managing their impulses and emotions. Given the confusion among all concerned - patients, staff and policymakers - about suicidality and self-harm, this area has remained largely untested, until recently. In light of the poor predictive power of the best instruments on suicidal intent, attention has turned to the nature of self-harming attempts. It is now accepted that it is very difficult, if not 
impossible, to distinguish between non-suicidal and suicidal self-harm attempts. Maddock and colleagues (2010) suggest that, in women with borderline personality disorder, any act of selfharm (other than superficial external injury to the skin) for which the patient seeks help or receives medical attention should be considered as likely to have been a suicidal act. In determining risks and likelihood of suicidality, they recommend that clinicians rely less on the patient's stated reasons for self-harm and more on the method used.

\section{Framework for risk assessment and management in secure institutions}

The NICE guidelines recommend developing risk assessment frameworks for homogeneous subgroups of patients, such that availability of a range of strategies for such groups might lead to a greater range and integration of models and skills of management (National Collaborating Centre for Mental Health 2004).

One such subgroup that places a huge cost on the NHS and the prison system are women with severe personality disorders (with or without Axis I disorders), with high rates of repeated self-harm and harm to others. The need for and challenges of developing risk management strategies are numerous in secure units. The rates of lifethreatening self-harm and suicide are relatively higher within secure institutions (Brooker 2010), with high rates of staff assaults (Uppal 2009). The sickness rates among staff in such units can often be an astounding 1 in 6, with 3479 calendar days lost to staff sickness over a 1-year period (Uppal 2009). This has a major impact on workforce morale, attitudes and capacity to care (Short 2009).

A framework document should therefore offer front-line nursing and medical staff principles, strategies and specific instructions to manage the consequences of repeated self-harm.

The key elements that a self-harm protocol should contain are summarised in Box 3. The principles highlighted in this article refer to adults of working age, with characteristics as listed in Box 4, and the nature and extent of self-harm as described in Box 5.

\section{Key elements in risk assessment}

The seminal work of Scott (1977), developing a framework for assessing risk of harm to others, suggests that any offence requires three key elements: an offender, a victim with particular characteristics, and prevailing circumstances or context. Extrapolating this to self-harm suggests that it too has three distinct elements: the person who carries out the act, the nature and severity of
BOX 3 Principles of a self-harm management protocol

- Identify patient group to be managed clinically

- Review relevant clinical histories

- Describe nature and severity of self-harm by this group

- Provide clear definitions of terms used for risk management

- Clinical strategies for distinguishing suicidal acts from self-harm

- Predicting future risk factors: high-risk acts, settings, objects to inflict harm, particular times of the day or days of the week, etc.

- Instructions to be simple, flexible, testable, userfriendly, and to empower front-line staff by providing knowledge and skills

- Predominantly objectively rather than subjectively determined by either staff or patient

the act, and the immediate set of circumstances within which the act is carried out. The patient provides the intention (Jamieson 1999), and the harm-causing potential of the act is demonstrated by its objective lethality (Skegg 2005). Finally, environmental factors that allow prolongation of the act determine its 'inimicality' (Shneidman 1981, 1996). The patient can influence the inimicality of the act by choosing or creating a setting in which it is more likely that maximum harm is caused, detection evaded and rescue prevented. An example of self-harm with high

BOX 4 Clinical characteristics of patients with personality disorders managed in secure units

- High levels of life-threatening self-harm and staff/carer assault

- Early age at onset of self-harm (often as early as 5-10 years)

- Disorders of attachment due to developmental trauma, chronic and complex trauma, abuse and neglect, usually by caregivers

- Primary diagnosis is often one of personality disorder

- Comorbidities of psychosis (e.g. drug-induced or acute and transient related to severe personality disorders), mood and anxiety disorders, substance misuse, eating disorders, somatisation, conversion and dissociative disorders

- History of serious harm to children and dependent others, arson and acquisitive offences

- History of violence towards staff 
BOX 5 Nature and severity of self-harm

\begin{tabular}{lc}
\hline $\begin{array}{l}\text { - Open wounds in subcutaneous and muscle } \\
\text { tissue }\end{array}$ & $\begin{array}{c}\text { - Pica: ingestion of chemicals, paper, } \\
\text { metal, glass, and self-poisoning }\end{array}$ \\
$\begin{array}{ll}\text { - Multiple re-insertion into old/new } \\
\text { surgical wounds }\end{array}$ & $\begin{array}{c}\text { B Bone injuries: fracturing limbs, } \\
\text { headbanging }\end{array}$ \\
- Interference with wound healing, & $\begin{array}{c}\text { - Internal soft tissue injuries: ingestion, } \\
\text { insertion of foreign bodies into body }\end{array}$ \\
reopening old wounds & orifices \\
- Insertion of foreign bodies into body & - Bloodletting requiring transfusion, \\
orifices & resuscitation \\
- Urogenital interference and mutilation & - Eyes: attempted blinding, injuring \\
- Occluding airway, suffocation, ligation, & sclera, conjunctiva \\
attempted hanging & Burning and scalding \\
- Contamination of wounds to prevent & - Cutting, laceration \\
healing by biological waste and &
\end{tabular}

inimicality is the successful suicide of a patient who leaves no suicide note, chooses a time of the day when staff are fewer (e.g. handover or medication times) or there are inexperienced or temporary staff on duty, and uses a piece of cloth hoarded for some time to hang themselves in a quiet and isolated part of the ward or hospital, having behaved normally with carers on the day of suicide. The significance of environmental factors such as low/no observations, access to objects and spaces, absence of experienced staff who know the patient well, and choice of time and day lies in the likelihood that this attempt ended in completed suicide.

It is important to make a distinction between intention/purpose, and motivation for the act. The former refers to causing a particular type of physical injury, whereas the latter refers to reasons

\section{TABLE 1 Lethality algorithm}

\begin{tabular}{|ll|}
\hline Lethality of the self-injury & Types of self-injury ('act') \\
\hline $\begin{array}{l}\text { Highly lethal } \\
\text { Traditional methods of suicide }\end{array}$ & $\begin{array}{l}\text { Hanging, strangulation, shooting, jumping from a high } \\
\text { place, poisoning }\left(\mathrm{CO}_{2} \text { gas, drugs, pesticides), stabbing, }\right. \\
\text { electrocution, drowning }\end{array}$ \\
\hline $\begin{array}{l}\text { Overdose, recreational drug overdose as self-harm, } \\
\text { cutting, burning }\end{array}$ \\
\hline $\begin{array}{l}\text { Less lethal } \\
\text { Self-injury with tissue damage } \\
\end{array}$ & $\begin{array}{l}\text { Symbols on skin, sticking needles or pins into skin, } \\
\text { interfering with wound healing }\end{array}$ \\
\hline & $\begin{array}{l}\text { Self-hitting, headbanging, fist against hard objects, } \\
\text { pinching, pulling hair }\end{array}$ \\
\hline $\begin{array}{l}\text { Non-lethal } \\
\text { Self-injury with no tissue damage }\end{array}$ & $\begin{array}{l}\text { Over-exercising, denying a necessity to hurt oneself, } \\
\text { stopping medications, starving with intent to cause } \\
\text { harm, tattoos, multiple body piercing }\end{array}$ \\
\hline & Deliberate recklessness with cars, drugs, trains, etc. \\
\hline
\end{tabular}

Italic text indicates acts that can belong to either of two categories: patients who are suicidal or cause tissue damage without death in the row above, or cause some or no tissue damage in the row below.

Adapted from Skegg 2005 behind the intention to cause a particular type of injury. Thus, patients may have motivational reasons that are variable, multiple and often confusing to themselves (Klonsky 2007), even though the intention is the same: to self-harm. It is suggested that intention can be derived from the nature or the injury caused, for presumably that is the purpose of the act (Maddock 2010). Sometimes the act is not fully executed, when patients with suicidal urges make abortive attempts because they do not know what the lethal dose or lethal injury would be. The opposite of this is equally true: patients with long histories of self-harm know the limits of harm they can cause 'safely' to themselves.

Although determination of intention is fraught (Harriss 2005) and correlation between intention (reasons for self-harm) and lethality (method of self-harm) poor (Beck 1975), it is suggested that assessing both can be 'most informative' (Hawton 2010). I believe that inclusion of an analysis of the prevailing environmental factors may enhance the nature of risk assessment even further.

\section{Strategies for assessing risk}

\section{Lethality (of the act)}

One might define lethality as the probability that a person's act of self-harm is likely to end in death. It has also been called the 'how quickly to death' question. The algorithm in Table 1 offers a way of determining lethality: as can be seen, lethality relates to the method of self-harm used.

\section{Intentionality (of the patient)}

If the ultimate purpose of someone who self-harms is to kill themselves, then intentionality can be defined as the individual's intensity of desire or wish to die. It is also referred to as the 'how likely to die' question, best inferred objectively from the nature and severity of self-harm. In that sense, it is closely entwined with the lethality of the act. The higher the intentionality, the greater the lethality of the act. Determination of intentionality should be as objective as is possible, owing to problems with subjectivity of patients and staff alike. Although intention cannot and should not be determined by behaviour alone, but assessed alongside environmental factors (see below) in the relatively controlled environments of institutions, it is possible to approximate, if not determine, real as opposed to stated or perceived intent.

\section{How to determine intentionality}

Attending medical and nursing staff should consider the method, sites and extent of injury, to gauge intention from the nature and severity of the act. 
High-risk methods Occlusion of airways is the major killer of people who self-harm as lack of oxygen leads to rapid alterations in consciousness and eventual brain damage and death if not rapidly managed. This would include all attempts where oxygen supply to the brain is affected, for example hanging (complete and partial), strangulation, suffocation, choking, drowning or placing heavy objects on oneself in order to prevent respiration. The affected sites are usually the head, neck and chest regions.

The NICE guidelines (National Collaborating Centre for Mental Health 2004) suggest that there are no safe limits to self-poisoning. Thus, any act of self-poisoning must be treated as potentially lethal. This includes the use of prescription, overthe-counter and illicit drugs, chemicals such as cleaning agents, toiletries (shampoo, soap), and acid contained in batteries that are swallowed.

The deeper the injury within the body, the riskier the act. The nature of internal injury is such that it cannot be seen and thus the extent of the damage is not known clinically, even if it can be known theoretically. There are high-risk injuries to regions of the body where any damage caused is likely to lead to serious consequences. These include cut, stab and insertion injuries to the heart, lung, head and eyes, urogenital mutilation and arterial cuts. The last is recognised by rhythmical spurts of bleeding where blood sprays rather than pools on the floor. It is misleading to the inexperienced eye, as there is no pooling of a large amount of blood, as happens in venous bleeding.

High-risk sites and extent of tissue damage/injury The extent of the injury is a function of the nature and severity of the injury, which in turn is a manifestation of the person's intentionality. It is a function of the depth as well as breath of the injury. Thus, it is important to establish whether the wound is due to stabbing (more risky than slicing or cutting), whether it bleeds in spurts due to cutting of an artery, a rapidly life-threatening injury (as opposed to bleeding heavily with pooling of blood due to venous cuts), or whether headbanging has caused a haematoma (swelling at the injury site) but there is no bleeding.

Insertion of foreign objects (e.g. blades, pens, staples, pins, nails) into deeper layers of tissue, especially if it is a new injury, is more risky and often requires immediate medical attention than placing objects in 'pockets' of scar tissue in subcutaneous fat. The latter does not tend to cause any serious injury as the patient is 'experienced' in removing the objects, the site is relatively sterile due to scar tissue (rather than 'live' tissue), and the objects can be removed relatively easily. In terms of the extent of the injury, burn injuries due to chemical burns (acids, other corrosives) cause more widespread injury (wider and deeper) than fire burns, unless the fire is significant. Similarly, a lacerating injury is wider than a neat cut and would take longer to heal, giving chances for wound interference later.

Certain acts are highly dangerous in terms of eventual lethality, even if the real intent of the patient is not to kill themselves. Thus, any act of self-poisoning, ingestion of liquids (more than solids), ingestion of sharp (more than blunt) objects, ingestion of leaking acid, lithium batteries (more than safety batteries), stabbing (more than cutting or slashing), and insertion of foreign objects into the vagina, urethra, anus, ears, nose and mouth (more than insertion into muscles and subcutaneous tissue) cause serious and potentially lethal injuries.

\section{Inimicality factors (the setting in which self-harm} occurs)

Inimicality or environmental factors refer to those actions by patients that make the prevailing circumstances unfavourable or unduly complicated in order to avoid detection by others, and thus increase the likelihood of serious harm or death. It can also be referred to as the 'How to avoid detection' question, and is best gauged by asking about the setting of the act: where, when, how, who was present, etc.

\section{How to determine high-risk settings}

The level of risk present in a particular setting depends on:

- the presence of hanging/ligature points;

- access to objects and implements that can be used to self-harm: e.g. sharp implements to cut, slash and stab, and potential ligature materials such as belts; more freely available objects such as jewellery, broken CDs, chemicals and drugs, which can be used to self-injure or ingest, should not be overlooked;

- access to spaces on or off the ward that have poor visibility (e.g. blind spots or lack of cameras), or lack staff constantly covering them (e.g. seclusion rooms), which can lead to a relative lack of observation and give the opportunity to engage in risky behaviour;

- high-risk periods, for example when staffing levels are low, staff are occupied in handovers or dispensing medications, or shifts with inexperienced staff;

- nursing shifts when self-harm is carried out for interpersonal influence (high-risk shifts, inexperienced, 'hated' or 'liked' staff, etc.). 
Within wards, access to objects with which a patient could self-harm can be limited on the basis of history of risky behaviour and currently assessed risks. At-risk patients should be placed on higher levels of observation. Is should be borne in mind that, even when observed every $5 \mathrm{~min}$, individuals with high levels of intentionality can secrete and hoard objects with which to self-harm in the future. Equally, observation every $15 \mathrm{~min}$ allows plenty of time for lethal attempts to be successfully completed. Access to spaces on/off the ward can be linked to observation levels and access to objects on the ward, which may be compromised off-ward. These inimicality factors and their management are covered in Table 2.

\section{Staff response and resource allocation}

Three principles, each derived from offender management within the criminal justice system, provide a useful framework for determining skill levels, quality and intensity of responses, and resource allocation in the management of high-risk repeated self-harm:

1 risk management - developing a skill base to assess and mange risk;

2 risk-need-responsivity principle - targeting the highest risk group with the highest amount of resource and skill;

3 dual risks - of harm to self and others, or of absconding, security breach, etc.

\section{Risk management}

In order to manage immediate treatment needs, front-line staff have to be well trained in basic hospital life support skills. These skills should include knowledge about the patient's medical history (e.g. asthma, bleeding disorder, epilepsy) and results of recent relevant blood tests. Staff should be able to recognise patients who are at risk of cardiac arrest, for example tachypnoea (respiration rate over 12-20 breaths/minute), tachycardia (heart rate over 100 beats/minute) or bradycardia (below 60 beats/minute), hypotension

\section{TABLE 2 Monitoring for inimicality factors}

\begin{tabular}{|ll|}
\hline Managing inimicality factors & What is being monitored \\
\hline $\begin{array}{l}\text { Manage observation (3:1 or 2:1 observation; line of } \\
\text { sight observation; frequency of observations) }\end{array}$ & Level of observation \\
\hline $\begin{array}{l}\text { Graded access to objects based on observation } \\
\text { levels }\end{array}$ & $\begin{array}{l}\text { Access to objects with which to self- } \\
\text { harm }\end{array}$ \\
\hline $\begin{array}{l}\text { Graded access to various parts of the ward, unit, } \\
\text { hospital based on level of observation and access } \\
\text { to objects }\end{array}$ & Access to spaces on/off ward \\
\hline $\begin{array}{l}\text { Manage personnel deployed on high-risk shifts } \\
\text { (e.g. nights, weekends, bank holidays) }\end{array}$ & $\begin{array}{l}\text { Access to certain staff profiles and } \\
\text { shifts }\end{array}$ \\
\hline
\end{tabular}

(systolic blood pressure below $100 \mathrm{mmHg}$ ) and enhanced capillary refill (more than 2 seconds). They should be able to recognise signs for abnormalities in airway, breathing, circulation and unconsciousness, and make a rapid initial assessment using the mnemonic AVPU (A, alertness; $V$, response to voice; $P$, response to pain; $U$, unresponsive).

Front-line staff should have received training and monitoring of immediate life support skills such as use of oxygen inhalation and ventilatory support, suction, positioning of the patient, advanced airway intervention, and management of choking.

In-patient wards must have available at all times D-size oxygen cylinders, breathing masks, airways of different sizes, hand-held suction pumps, pocket masks, electrocardiogram and defibrillator equipment with electric suction. This equipment should be kept in an identified location on the ward and it must be checked regularly to ensure that it is operational. Staff should have access to and be registered with the National Poisons Information Service (www.toxbase.org).

\section{The risk-need-responsivity principle}

This risk-need-responsivity model is perhaps the most influential model for the assessment and treatment of offenders (Andrews 2006). Although developed for offenders, the principles of the approach can be adapted for use with anyone with behavioural problems (e.g. self-harm, eating disorder). The three core principles are outlined below.

\section{Risk principle}

Match the level of intervention to the patient's risk behaviour (e.g. self-harm, violence, eating disorder, impulsivity); the higher the level of risk, the more enhanced and complex the level of intervention and therefore service structure.

\section{Need principle}

Assess specific psychological needs and target them in treatment, for example, pharmacotherapy and cognitive-behavioural therapies for patients with schizophrenia, and enhanced psychological treatments to manage attachment and esteem needs for patients with bipolar disorder.

\section{Responsivity principle}

Mapping service delivery to the capacity of the patient to maximise their learning from the intervention. This presupposes that services have to adapt their treatment delivery to meet patient requirements and not the other way around. Many 
patients are labelled 'untreatable' as services do not tailor treatment delivery in a manner that benefits the patient and instead expect patients to adapt themselves to what is on offer.

\section{Dual risks}

In this patient group additional risks may be present, such as harm to others (including serious assaults and even death) and attempts to breach security and abscond. Absconding is an immediate concern when patients have to be taken to A\&E following serious self-harm. The dual risks of selfharm in tandem with serious violent assaults on staff are a feature of secure institutions. This often leads to patients being nursed in seclusion (or, in prisons, in segregation).

\section{Managing dual risks in seclusion}

Every institution has a duty, as do individual members of staff, to provide care and treatment to patients detained for their health and safety and protection of others. The institution and the responsible clinician face risks of claims of negligence by patients if staff do not intervene for fear of being assaulted or deny access to objects that compromise patients' basic human rights. High secure units also face legal action by staff for not taking adequate care or providing protection to their employees when there is a known risk of serious assault. The 2008 revision of the Mental Health Act Code of Practice states that 'seclusion should not be used where there is any risk of suicide or self-harm' (Department of Health 2008: p. 123). However, following claims of gross negligence by staff against their employers, case law has now determined that employers have an obligation to seriously consider the use of seclusion to protect staff/others when there is a major risk of serious assault. As a result, the 2008 revision also allows the seclusion of people who self-harm when there is a risk of serious harm to others. An appropriate balance between ensuring patient safety and staff safety must be struck.

Patients with propensity to cause harm to others when prevented from self-harming often report that self-harm leads to an intense feeling of relief and liken it to an addiction. There is evidence that repeated self-harm raises the level of circulating opioids in the body such that there is a 'chemical dependence' followed by a 'craving' to self-harm. It is therefore sensible that, before considering seclusion, clinicians undertake a trial of opiate medication for the management of intractable and 'addictive' self-harm. Prescribing opioids reduces the analogous drug-(opiate)-seeking addictive behaviour that repeated self-harm

comes to represent for patients (Roth 1996; Sonne 1996; Philipsen 2004). The relief they sought from repeated self-harm is provided by the opioid medication, thus reducing the inner need to assault the self (and others). The suggested strategies in Box 6 might inform self-harm management policies where dual risks are present.

\section{Risk management protocol for self-harm}

The foregoing principles and strategies are contained within an algorithm (Table 3). This algorithm translates the practical points into a hierarchical sequential model of risk management. Within this algorithm, risk status in terms of potential lethality, intentionality and environmental factors is highlighted at various levels of risk and is linked to necessary staff responses. Each successive level of risk and required responses build on the risks and responses at previous levels.

The algorithm described in Box 3 has been tested to staff satisfaction with a high-risk patient group over an 18-month period (Sarkar 2001a). Significantly, during this time there were no deaths, very few serious untoward incidents (fewer than five) and relatively limited complications related to self-harm and long-term injuries. There were several incidents of simultaneous risks of harm to self and others, when patients were managed in seclusion, with no undue risks to either patients or staff. During this period, many patients who had been self-harming for years and decades have stopped self-harming altogether. Staff find basic

B0X 6 Managing simultaneously dual risks of harm to self and others

- Patients must never be secluded simply to prevent self-harm

- The nature and degree of risk to others must be documented, with evidence listed of injuries caused to others, attempts to manage risk to others using less restrictive means and use of alternatives to seclusion

- Alternatives to seclusion include: pharmacotherapy using local rapid tranquillisation policies or opiates physical restraint by staff, although this runs the risk of more frequent staff assaults owing to close proximity and ability of patients to spit at, bite and scratch staff

in exceptional cases, use of mechanical restraint, which includes restrictive garments, emergency response belts or furniture (specially designed with limb restraints)
- Where headbanging is the major self-harm risk, consideration should be given to the creation of a 'padded' seclusion room

- Documentation must be necessarily detailed to justify overriding the need to protect staff/others

- The specific risks to self while in seclusion (type, severity, probability) should be detailed with reference to past behaviours within or outside seclusion

- Explicit guidance to be available for staff on when to intervene in the event of selfharm when in seclusion

- A second opinion should be sought before engaging in practice that is restrictive as this provides a level of external scrutiny

- Ongoing practice should also be externally reviewed by senior clinicians and national experts who have sufficient experience in the field 
hospital life support training to be very useful and use the general approach to keep communicating with the patient and make dynamic assessment of the risk of harm. They find it important to understand each patient with their unique risk factors and triggers, with individualised care plans which detail specific management strategies for specific forms of self-harm. As such, this approach is consistent with the notion of 'personalisation' of care, a key principle in the government's document New Horizons (Department of Health 2009).

Such an algorithm could be an essential guide for busy front-line clinicians, as it provides a set of clear instructions that are simple, clinically flexible and potentially testable against ongoing clinical practice. It helps relatively inexperienced and junior nursing and medical staff, who often form the first line of response to repeated selfharm, devise sophisticated care plans even if senior clinicians cannot be immediately contacted for advice. It allows rapid judgements on current risks and required responses. Such a protocol should build on practice that has its foundation in the policy and procedures of the secure unit. All staff should be trained from the outset in these principles, with clinical team leaders ensuring that training and support are at optimal levels. Theoretical principles must be regularly checked against prevailing practice and, if necessary, theoretical models should be updated or altered accordingly. This iterative process will ensure fidelity between the model and clinical practice. It is essential to seek staff views and their satisfaction with the model, as however meaningful it might be to senior clinicians and managers, if it does not help front-line staff, they are unlikely to use it.

\section{Conclusions}

Repeated self-harm leads to high rates of mortality and morbidity, and even though many more patients harm themselves than others, self-harm has been the subject of less attention. One reason for this might be the government's reluctance to invest in an area that does not capture public imagination as much as the idea of random violence by people with mental illnesses. Unfortunately, for years psychiatrists have been responsible for neglecting this area, first by turning away people with diagnoses of personality disorder who selfharm (National Institute for Mental Health in

\section{TABLE 3 Risk algorithm for the assessment and management of high-risk self-harm and risks of assault to carers}

\begin{tabular}{|c|c|c|}
\hline Situation & Risk level & Response \\
\hline $\begin{array}{l}\text { Little blood loss, injury skin deep, gentle and infrequent } \\
\text { headbanging. }\end{array}$ & $\begin{array}{l}\text { Level } 1 \\
\text { Lethality low } \\
\text { Intentionality low } \\
\text { Inimicality low }\end{array}$ & $\begin{array}{l}\text { Support patients in cleaning wounds } \\
\text { Carried out by junior nursing staff under supervision of nurse } \\
\text { in charge. }\end{array}$ \\
\hline $\begin{array}{l}\text { Deeper cuts involving subcutaneous tissue, requires suturing. } \\
\text { Head-banging gentle and infrequent. }\end{array}$ & $\begin{array}{l}\text { Level } 2 \\
\text { Lethality low } \\
\text { Intentionality low } \\
\text { Inimicality moderate }\end{array}$ & $\begin{array}{l}\text { Involve medical staff and senior nursing staff to treat injury } \\
\text { and provide support to patient and other patients. }\end{array}$ \\
\hline $\begin{array}{l}\text { Insertion of foreign bodies into subcutaneous scar tissue } \\
\text { 'pockets' created through similar acts in the past ('old' wounds). } \\
\text { More intense headbanging. Severe forceful injury to self } \\
\text { (usually acute one-off or one or two such incidents) leading to } \\
\text { bony fractures. Burning or scalding self. Venous cuts leading to } \\
\text { pooling of a large amount of blood. }\end{array}$ & $\begin{array}{l}\text { Level } 3 a \\
\text { Lethality low } \\
\text { Intentionality moderate } \\
\text { Inimicality moderate }\end{array}$ & $\begin{array}{l}\text { Activate panic alarms to secure additional staff for support } \\
\text { and advice. Senior nurses and medical/primary healthcare } \\
\text { help sought. Senior nursing duty coordinator and charge } \\
\text { nurse jointly manage the situation. }\end{array}$ \\
\hline $\begin{array}{l}\text { Insertion of foreign bodies into subcutaneous tissue - puncture } \\
\text { or stab wounds - 'new'. Depth of wounds can include muscles } \\
\text { and other organs and tissue. Significant blood loss, acute } \\
\text { emergency, spurting of blood due to arterial cut. Repetitive } \\
\text { headbanging leading to haematoma. }\end{array}$ & $\begin{array}{l}\text { Level } 3 b \\
\text { Lethality moderate to high } \\
\text { Intentionality high } \\
\text { Inimicality moderate to high }\end{array}$ & $\begin{array}{l}\text { On occasions, especially when fractures are suspected, } \\
999 \text { calls made and A\&E trips organised. In such cases duty } \\
\text { consultant/responsible clinician informed. Ward managers } \\
\text { informed if available, and senior nursing managers involved. }\end{array}$ \\
\hline $\begin{array}{l}\text { Self-poisoning with medications, other chemicals (soap, } \\
\text { washing liquid, cleaning agents, etc.). Serious attempts to } \\
\text { self-ligate, choke or occlude airway through any means. Head- } \\
\text { banging severe, intense, repetitive with patient beginning to } \\
\text { stagger. }\end{array}$ & $\begin{array}{l}\text { Level } 4 \\
\text { Lethality high } \\
\text { Intentionality high } \\
\text { Inimicality high } \\
\text { Other risks low }\end{array}$ & $\begin{array}{l}\text { Senior nursing input. Medical and primary healthcare } \\
\text { staff always involved. Low threshold for requesting } 999 \\
\text { ambulance support for A\&E transfer. }\end{array}$ \\
\hline $\begin{array}{l}\text { Self-harm in seclusion room. Patient requiring immediate } \\
\text { transfer to A\&E on secure escort, high risk of staff assault, } \\
\text { absconding. }\end{array}$ & $\begin{array}{l}\text { Level } 5 \\
\text { Lethality high } \\
\text { Intentionality high } \\
\text { Inimicality high } \\
\text { Other risks high: harm to others, } \\
\text { absconding, security breach }\end{array}$ & $\begin{array}{l}\text { Hand-cuffs for out-of-hospital trips. Responsible clinician/ } \\
\text { consultant, senior managers always informed. Explicit } \\
\text { guidance on when to intervene. Always use a response team. } \\
\text { Proportionate response balancing risks of harm to others } \\
\text { against harm to self and staff duty to protect life and limb. }\end{array}$ \\
\hline
\end{tabular}

A\&E, accident and emergency department. 
England 2003), and second because of a lack of interest in this issue (Royal College of Psychiatrists 2010). This may be so because risk assessment and risk prediction are notoriously difficult and there is little funding for the treatment of self-harm within the NHS (Royal College of Psychiatrists 2010). Nevertheless, clinicians can begin to address the problem practically, by developing local protocols and audit standards that are subjected to rigorous clinical testing, with surveys of staff and patients, and submitted for systematic research.

\section{References}

Andrews D, Bonta J (2006) The Psychology of Criminal Conduct (4th edn). LexisNexis.

Appleby L, Shaw J, Kapur NN, et al (2006) Avoidable Deaths: Five Year Report of the National Confidential Inquiry into Suicide and Homicide by People with Mental IIIness. Department of Health.

Beck AT, Beck R, Kovacs M (1975) Classification of suicidal behaviors: I. Quantifying intent and medical lethality. American Journal of Psychiatry 132: 285-7.

Brooker C, Flynn J, Fox C (2010) Trends in self-inflicted deaths in prisons in England and Wales (2001-2008): towards targeted interventions. Journal of Aggression, Conflict and Peace Research 2: 34-43.

Department of Health (2008) Code of Practice: Mental Health Act 1983. TSO (The Stationery Office).

Department of Health (2009) New Horizons: A Shared Vision for Mental Health. Department of Health.

Fazel S, Cartwright J, Norman-Nott A, et al (2008) Suicide in prisoners: a systematic review of risk factors. Journal of Clinical Psychiatry 69 : $1721-31$.

Gallagher J, Sheldon K (2010) Assessing the functions of self-harm behaviours for dangerous and severe personality disordered males in a high secure hospital. British Journal of Forensic Practice 12: 22-32.

Gulland A (2007) Prison inspector's report slates mental health provision. BMJ 335: 902.

Gunnell D, Miller M (2010) Strategies to prevent suicide. BMJ 341: c3054.

Harriss L, Hawton K (2005) Suicidal intent in deliberate self-harm and the risk of suicide: the predictive power of the suicide intent scale. Journal of Affective Disorders 86: 225-33.

Hawton K (2010) Completed suicide after attempted suicide: methods used in attempts may indicate the degree of risk. BMJ 341: 158-9.

Howard League of Penal Reforms (2003) Suicide and Self-Harm Prevention: The Management of Self-Injury in Prison. Howard League of Penal Reforms.

Jamieson KR (1999) Night Falls Fast: Understanding Suicide. Knopf Doubleday Publishing Group.

Klonsky ED (2007) The functions of deliberate self-injury: a review of the evidence. Clinical Psychology Review 27: 226-39.

Larkin E, Murtagh S, Jones S (1988) A preliminary study of violent incidents in a special hospital (Rampton). British Journal of Psychiatry 153: 226-31.

Maddock G, Carter G, Murrell E, et al (2010) Distinguishing suicidal from non-suicidal deliberate self-harm events in women with borderline personality disorder. Australian and New Zealand Journal of Psychiatry 44: 574-82.

Meltzer H, Lader D, Corbin T, et al (2002) Non-Fatal Suicidal Behaviour Among Adults Aged 16 to 74 in Great Britain. TSO (The Stationery Office).

Mitchell A, Dennis M (2006) Self-harm and attempted suicide in adults: 10 practical questions and answers for emergency department staff. Emergency Medicine Journal 23: 251-5.
National Collaborating Centre for Mental Health (2004) Self Harm: The Short-Term Physical and Psychological Management and Secondary Prevention of Self-Harm in Primary and Secondary Care. The British Psychological Association \& The Royal College of Psychiatrists.

National Confidential Inquiry into Suicide and Homicide by People with Mental Illness (2009) Annual Report: England and Wales. University of Manchester.

National Institute for Mental Health in England (2003) Personality Disorder: No Longer a Diagnosis of Exclusion. Department of Health.

Nisbett R, Wilson T (1997) Telling more than we can know: verbal reports on mental processes. Psychological Review 84: 231-59.

Perseuis K-I, Kaver A, Ekdahl S, et al (2007) Stress and burnout in psychiatric professionals when starting to use dialectical behaviour therapy in the work with self-harming women showing borderline personality symptoms. Journal of Psychiatric and Mental Health Nursing 14: 635-43.

Philipsen A, Richter H, Schmahl C, et al (2004) Clonidine in acute aversive inner tension and self-injurious behavior in female patients with borderline personality disorder. Journal of Clinical Psychiatry 65: 1414-9.

Reulbach U, Bleich S (2008) Suicide risk after a suicide attempt. BMJ 337: a2512.

Roth AS, Ostroff RB, Hoffman RE (1996) Naltrexone as a treatment for repetitive self-injurious behavior: an open-label trial. Journal of Clinical Psychiatry 57: 233-7.

Royal College of Psychiatrists (2010) Self-Harm, Suicide and Risk: Helping People who Self-Harm (College Report CR158). Royal College of Psychiatrists.

Runeson B, Tidemalm D, Dahlin M, et al (2010) Method of attempted suicide as predictor of subsequent successful suicide: national long term cohort study. BMJ 341: 186-7.

Sarkar J (2010) From science to services: developing a neurosciencebased innovative clinical treatment model to manage severe and repetitive self-harm in a 60 -year-old woman with severe personality disorder. Personality and Mental Health 4: 302-11.

Sarkar J Beeley C (2011a) Developing an algorithm of a hierarchical model of short-term management of repetitive self-harm among women with severe personality disorders in medium security. Journal of Forensic Psychiatry and Psychology in press.

Sarkar J, di Lustro M (2011b) Evolution of secure services for women in England. Advances in Psychiatric Treatment 17: 323-31.

Scott PD (1977) Assessing dangerousness in criminals. British Journal of Psychiatry 131: 127-42.

Shneidman E (1981) Suicide thoughts and reflections. Suicide and LifeThreatening Behavior 11: 198-231.

Shneidman E (1996) The Suicidal Mind. Oxford University Press.

Short V, Cooper J, Shaw J, et al (2009) Custody vs care: attitudes of prison staff to self-harm in women prisoners - a qualitative study. Journal of Forensic Psychiatry and Psychology 20: 408-26.

Skegg K (2005) Self harm. Lancet 366: 1471-83.

Sonne S, Rubey R, Brady K, et al (1996) Naltrexone treatment of selfinjurious thoughts and behaviors. Journal of Nervous and Mental Diseases 184: 192-5.

Tantam D, Huband N (2009) Understanding Repeated Self-Injury: A Multidisciplinary Approach. Palgrave-Macmillan.

Uppal G, McMurran M (2009) Recorded incidents in a high-secure hospital: a descriptive analysis. Criminal Behaviour and Mental Health 19: 265-76.

Walsh B (2009) Strategies for responding to self-injury. When does the duty to protect apply? In The Duty to Protect: Ethical, Legal and Professional Considerations for Mental Health Professional (eds J Werth, E Welfel, G Benjamin): 181-93. American Psychological Association.

Zahl DL, Hawton K (2004) Repetition of deliberate self-harm and subsequent suicide risk: long-term follow-up study of 11583 patients. British Journal of Psychiatry 185: 70-5. 
MCQs

Select the single best option for each question stem

1 Suicide is:

a one of the ten leading causes of death globally

b not a major public health problem

c responsible for thousands of deaths worldwide every year

d responsible for hundreds of deaths in the UK every year

e the leading cause of death globally.

\section{Which of the following methods is least} associated with death in attempted suicide?

a hanging

b gas inhalation c drowning

d firearm use

e self-cutting.

3 Factors not associated with suicide in prisons include:

a being an inmate in a single cell

b recent suicidal ideation

c history of attempted self-harm

d not having a psychiatric diagnosis

e history of alcohol misuse.

4 Key elements in self-harm risk assessment include all except:

a intention of the patient

b inimicality of circumstances c lethality of the act

d psychiatric diagnosis

e suffering from mania.

5 Managing dual risks of harm to self and others include:

a allowing patients to choose when to self-harm

b providing access to clean blades with which to self-harm

c provision of self-help groups where patients can share their experiences

d secluding patients who use self-harm as a way to gain access to staff, whom they can then assault

e seeking second opinion from experts when using restrictive practices 